\title{
The Effects of the Leadership Style on the Learning Motivation of Students in Elementary Schools
}

\author{
Mei-Hui Lin ${ }^{1}$, Tsai-Fu Chuang ${ }^{2 *}$ \\ ${ }^{1}$ Department of Business Innovation and Development, MingDao University, Changhua, Taiwan; ${ }^{2}$ Department of Design for Sus- \\ tainable Environment, MingDao University, Changhua, Taiwan. \\ Email: * $\underline{\text { tfchuang@mdu.edu.tw }}$ \\ Received October $10^{\text {th }}, 2013$; revised November $12^{\text {th }}, 2013$; accepted December $5^{\text {th }}, 2013$ \\ Copyright (C) 2014 Mei-Hui Lin, Tsai-Fu Chuang. This is an open access article distributed under the Creative Commons Attribution \\ License, which permits unrestricted use, distribution, and reproduction in any medium, provided the original work is properly cited. \\ In accordance of the Creative Commons Attribution License all Copyrights (C) 2014 are reserved for SCIRP and the owner of the \\ intellectual property Mei-Hui Lin, Tsai-Fu Chuang. All Copyright (C) 2014 are guarded by law and by SCIRP as a guardian.
}

\section{ABSTRACT}

This major objective of this study is to investigate the effect of leadership styles of science teachers on the learning motivation of elementary school students. It is generally known that students' learning motivation could affect the learning achievement. Besides, students with strong learning motivation generally lead to better learning performance. If a teacher can break through the tradition and adopt a creative leadership style, it is possible to increase the learning motivation and result in better learning achievement. In this study, 165 primary school teachers and $\mathbf{2 8 0 0}$ students were randomly selected. Leadership styles and learning motivation questionnaires were designed for research instruments. In the data analysis, descriptive statistics analysis, Pearson correlation analysis, multiple regression analysis were adopted. The results showed that: 1) Both the transformational and transactional leadership styles have been employed by elementary school teachers in this study. 2) The correlations between the above two leadership styles and the learning motivation of students are both "moderate to good relationship”. 3) The transformational and the transactional leadership styles can explain $52.60 \%$ of variance for the learning motivation of students. 4) Multiple regression analysis can be used to infer causal relationships between the leadership styles of teachers and the learning motivation of students.

\section{KEYWORDS}

\section{Improving Classroom Teaching; Elementary Education}

\section{Introduction}

All over the world, teaching is one of the most complicated jobs nowadays. It requires broad knowledge of the subject matter, curriculum, enthusiasm, and a lot of learning, knowledge of discipline and advanced leadership styles. Many studies suggested the single most important factor determining the quality of the education a child receives is the quality of his teacher.

Leadership has always been a contentious issue among many researchers. Thousands of papers and hundreds of researches have been done on this topic [1]. Robbins and Coultar [2] proposed the leadership as "process of influencing a group towards the achievements of goals". He also defined the leader as "someone who can influ-

${ }^{*}$ Corresponding author. ence others and who has managerial authority". The performance of any group can be set by the performance of the leader. If the leader's performance is high, then the performance of the groups will also be high [3].

There is an old saying "Birds of a feather flock together" which implies that birds of the same species (i.e. with similar plumage) often tend to gather to feed or migrate together. It also means that people who are similar will spend more time together because they have something in common. In other words, this also shows that people will become similar if they spend more time together. A great Chinese teacher, Confucius (551 - 479 B.C.), also said, "When I walk along with two others, they may serve me as my teachers. I will select their good qualities and follow them". The above Confucian Analects can also be interpreted as that each member of the 
group will be affected by other members.

In this study, we try to investigate the effects of the leadership style on the learning motivation of students. The goals of this study were showed as follows:

1) To survey the leadership styles of science teachers and the learning motivation of students.

2) To investigate the correlation between leadership styles of teachers and the learning motivation of students.

3) To investigate the causal relationship between leadership styles of teachers and the learning motivation of students.

\section{Literature Review}

\subsection{Concept of Leadership}

Leadership has always been the subject of human study. This topic has been investigated by researchers, philosophers and historians time and again $[4,5]$. In psychology, trait theory is an approach to the study of human personality. Trait theorists are primarily interested in the measurement of traits, which can be defined as habitual patterns of behavior, thought, and emotion [6]. In twentieth century, trait theories on leadership and motivation were started and after that philosophers and researchers start working on the formal theories of leadership. From 1920-1960 researchers tried to find the leader's personality and character of leadership [7].

A famous idiom "There are no poor soldiers under a good general" can be taken as a good example to illustrate a great leadership principle. Those individuals are considered to the great leaders who can change themselves according to the demand of the situations. These individuals can adopt the pattern of leadership according to the needs [8]. There is a good example in human history. It is well known that Dr. Sun Yat-sen (1866-1925) was a Chinese revolutionary, first president and founding father of the Republic of China ("Nationalist China”). He originally worked as a medical doctor to rescue the sick people, but he was then transformed to be a revolutionary aiming to rescue the whole Chinese. It is very difficult to believe that a medical doctor can lead and influence so many followers to overthrow such a big country with 400 million people. Dr. Sun played an instrumental role in the overthrow of the Qing dynasty. From the above illustration, Dr. Sun is no doubt to be a great leader with very great leadership styles.

\subsection{Teacher Belief, Culture and Leadership}

Teacher beliefs are proposed to be an indicator for certain students' behaviors because of the mediating effects of beliefs on the ways of teaching via their impact on decision making $[9,10]$. For example, teachers who believed that collaborative learning could bring greater benefits than learning alone would tend to include more group work than teachers who see little or no learning value in collaboration. Furthermore, teacher beliefs are regarded as one of the most valuable constructs for teacher education $[9,11]$. Beliefs can guide teachers' behavior either deliberately or spontaneously. In a deliberate way beliefs are retrieved or constructed with a lot of effort in a certain context and they are assumed to guide goal setting and behavior. In a spontaneous way beliefs are activated by routine [12].

Culture is a modern concept based on a term first used in classical antiquity by the Roman orator Cicero: "cultura animi” (cultivation of the soul). This non-agricultural use of the term "culture" re-appeared in modern Europe in the 17th century referring to the betterment or refinement of individuals, especially through education [13]. Culture, or the way people behave in an organization can influence how a leader evaluates the performance of a group. Rhodes, Walsh and Lok state that the "development of a high-performance culture requires the inspiration, drive, and commitment of the leader, leadership is critical to the change process underpinning the Balanced Scorecard" [14]. Besides, according to the above authors, cultural values tend to have important implications on management practices, because "there is a positive relationship between a high performance culture and the adoption of best practices" [14]. For instance, the United States' culture is considered to be high performance and, if organizations are to remain competitive, they must employ best practices from around the globe. Some of these best practices may include the training and development of effective ethical leaders through successsion planning and development because effective leaders require vision, knowledge, and execution skills [15].

\subsection{Transformational Leadership Style}

Transformational leadership enhances the motivation, morale, and performance of followers through a variety of mechanisms. These include connecting the follower's sense of identity and self to the project and the collective identity of the organization; being a role model for followers that inspires them and makes them interested; challenging followers to take greater ownership for their work, and understanding the strengths and weaknesses of followers, so the leader can align followers with tasks that enhance their performance [13].

James MacGregor Burns [16] was the first who introduced the concept of transforming leadership in his descriptive research on political leaders, but this term is now used in organizational psychology as well [17]. According to Burns, transforming leadership is a process in which "leaders and followers help each other to advance to a higher level of morale and motivation”. Burns [16] related to the difficulty in differentiation between management and leadership and claimed that the differences 
are in characteristics and behaviors. He has also established two concepts: "transforming leadership" and "transactional leadership". According to the concepts of Burns, the transforming approach creates significant change in the life of people and organizations. It redesigns perceptions and values, and changes expectations and aspirations of employees. Unlike in the transactional approach, it is not based on a "give and take" relationship, but on the leader's personality, traits and ability to make a change through example, articulation of an energizing vision and challenging goals [13]. Transforming leaders are idealized in the sense that they are a moral exemplar of working towards the benefit of the team, organization and/or community. Burns [16] theorized that transforming and transactional leaderships were mutually exclusive styles.

Bernard M. Bass [18] extended the concept of Burns [16] by explaining the psychological mechanisms that underlie transforming and transactional leadership. Bass proposed the term "transformational" in place of "transforming." Bass added to the initial concepts of Burns [16] to help explain how transformational leadership could be measured, as well as how it impacts follower motivation and performance. The extent to which a leader is transformational is measured first, in terms of his influence on the followers. The followers of such a leader feel trust, admiration, loyalty and respect for the leader and because of the qualities of the transformational leader are willing to work harder than originally expected. These outcomes occur because the transformational leader offers followers something more than just working for self gain. They provide followers with an inspiring mission and vision and give them an identity. The leader transforms and motivates followers through his or her idealized influence (earlier referred to as charisma), intellectual stimulation and individual consideration. In addition, this leader encourages followers to come up with new and unique ways to challenge the status quo and to alter the environment to support being successful. Finally, in contrast to Burns, Bass [18] believed that leadership can simultaneously display both transformational and transactional leadership.

\subsection{Transactional Leadership Style}

Within the context of Maslow's hierarchy of needs, transactional leadership works at the basic levels of need satisfaction, where transactional leaders focus on the lower levels of the hierarchy. Transactional leaders use an exchange model, with rewards being given for good performance or positive outcomes. Conversely, people with this leadership style also can punish poor achievement or negative outcomes, until the problem is corrected [18]. Transactional leadership is related to motivating the employees and making them do the works with the help of external motivators such as organizational rewards [19]. Transactional leadership style focuses on the role of supervision, organization, and group performance, etc. As Tengilimoğlu [20] proposed that transactional leader generally works with a focus on continuing the works of the past and transferring them to future.

In general, transactional leadership has four dimensions: Conditional reward, management by exceptions (active), management by exceptions (passive) and laissez-faire [19,21]. Contingent reward means a process of mutual transaction where leader is trying to motivate the followers by rewards and promises [22]. Management by exceptions (active) is about leader's observing employees' performance and correcting their mistakes [18]. Management by exceptions (passive) implies leader's not intervening the organizational problems until they acquire a stricter situation and not acting before any kind of mistakes occurs [21]. Laissez-faire is a leadership style in which the leader never intervenes the administrative processes and gives limitless freedom to the followers $[21,22]$. One way that transactional leadership focuses on lower level needs is by stressing specific task performance. Transactional leaders are effective in getting specific tasks completed by managing each portion individually [18].

\subsection{Leadership Style and Motivation}

Motivation is a psychological feature that arouses an organism to act towards a desired goal and elicits, controls, and sustains certain goal-directed behaviors. It can be considered a driving force; a psychological one that compels or reinforces an action toward a desired goal [23]. In generally, it gets students moving, points them in a particular direction, and keeps them going. We often see students' motivation reflected in personal investment and in cognitive, emotional, and behavioral engagement in school activities [24].

Generally, most students are motivated in one way or another. Some student may be keenly interested in classroom subject matter and seek out challenging course work, participate actively in class discussions, and earn high marks on assigned projects. Another student may be more concerned with the social side of school, interacting with classmates frequently, attending extracurricular activities almost every day, and perhaps running for a student government office [25].

However, motivation is not necessarily something that students should bring to schools; it can also arise from environmental conditions at schools. When we think about how the environment can enhance a student's motivation to learn particular things, we are talking about situated motivation [26,27]. In the pages to come, we'll find that as teachers, they can do so many things to motivate students to learn and behave in ways that promote 
their long-term success and productivity [23].

Typically, the school organization has a principal or headmaster as its primary leader, and a classroom organization has a teacher as its primary leader. A primary leader in classroom is someone who models, motivates, and initiates acts of leadership. In general, the leader pulls the organization to higher ground or to better achievement. It should be noted that this is different from pushing. Pushing can also motivate, but it is based on the avoidance of negative consequences.

In Taiwan, The Ministry of Education revised the Education Fundamental Act in 2005 which forbade the corporal punishment. Therefore, the traditional authoritative leadership styles must be modified to adapt to the present educational environment. Consequently, both the transformational leadership and transactional leadership styles have become the mainstream of education and hot research topics. Research results [28] showed that if teachers adopted both transformational leadership and transactional leadership styles, students usually had high academic performance. Besides, if teachers adopted only transactional leadership styles, students generally had low academic performance.

Up to now, related researches on this topic are still rather minor. Consequently, there is a need to conduct a research to establish if there is a relationship between teacher's leadership styles and learning motivation of students. The results could provide a useful material for the principal, and ministry of education.

\section{Methods and Materials}

\subsection{Research Questions}

This study was designed to address the following research questions:

1) What are the leadership styles of science teachers in this study?

2) Is there a correlation between leadership styles of teachers and learning motivation of students?

3) Is there a causal relationship between leadership styles of teachers and learning motivation of students?

\subsection{Participants}

The study was carried out with a total of 200 teachers from 171 primary schools in Changhua Couny of Taiwan (Figure 1). The number of returned and questionnaires is 165 , the returned rate is $83 \%$, invalid questionnaires are 0 , effective questionnaires are 165 , and the returned rate of effective questionnaires is $83 \%$, respectively. Of all the primary teachers participating in the study, $50.5 \%$ are male and $49.5 \%$ are female. Of all the primary students participating in the study, $54.9 \%$ are male and $45.1 \%$ are female.

\subsection{Instruments}

In this study, we have designed two questionnaires which combined the results of the literature reviews of our survey.

1) Leadership questionnaire:

A questionnaire was designed by the authors mainly based on the leadership theory proposed by Bass [18], and literature reviews of Huang [28]. The above questionnaire was then divided into two parts. The first part included 4 sets of factors and 12 fill-in items aimed to explore the transformational leadership style. The 4 sets of factors are charisma influences, stimulating motivation, intellectual stimulation and individualized consideration. The second part included 3 sets of factors, and 9 fill-in items aimed to explore the transactional leadership style. The 3 sets of factors are mutually beneficial award, active management, and passive management. The items are rated on a five-point rating scale of Likert Type including "very agree” with "5”, “ agree” with "4”, "partially agree" with "3", "disagree” with "2", "extremely disagree" with " 1 ".

2) Learning motivation questionnaire:

Another questionnaire was designed by the authors mainly based on the "Motivated Strategies for Learning Questionnaire (MSLQ)" proposed by Wu and Cherng [29], and the questionnaire proposed by Pintrich, Smith, Garcia and Mckeachie [30]. In this study, the proposed questionnaire also referred the "learning motivation questionnaire" proposed by Huang [31]. This questionnaire included 3 sets of factors, and 14 fill-in items. The 3 sets of factors are value, expectancy, and affective factors.

To ensure and enhance the reliability and validity of the questionnaire, Cronbach's Alpha coefficient, corrected item-total correlation and factor analysis available in SPSS are selected in this study.

Cronbach's Alpha determines the internal consistency or average correlation of items in a survey instrument to gauge its reliability. Nunnaly [32] has proposed 0.7 to be an acceptable reliability coefficient but lower thresholds are sometimes used in the literature. The item-total correlation is a correlation between the question score and the overall assessment score. It is expected that if a participant gets a question correct they should, in general, he should have a higher overall assessment score than participants who get a question wrong. Also, it is generally accepted that the minimum value for this (item-total correlation) is 0.3 .

Factor Analysis is a technique for finding a small number of underlying dimensions from among a large number of variables. This technique was used in this study to explore the possible underlying factor structure. By performing factor analysis, the underlying factor is identified, and data reduction can be achieved. There are generally two steps in factor analysis: namely, the ex- 


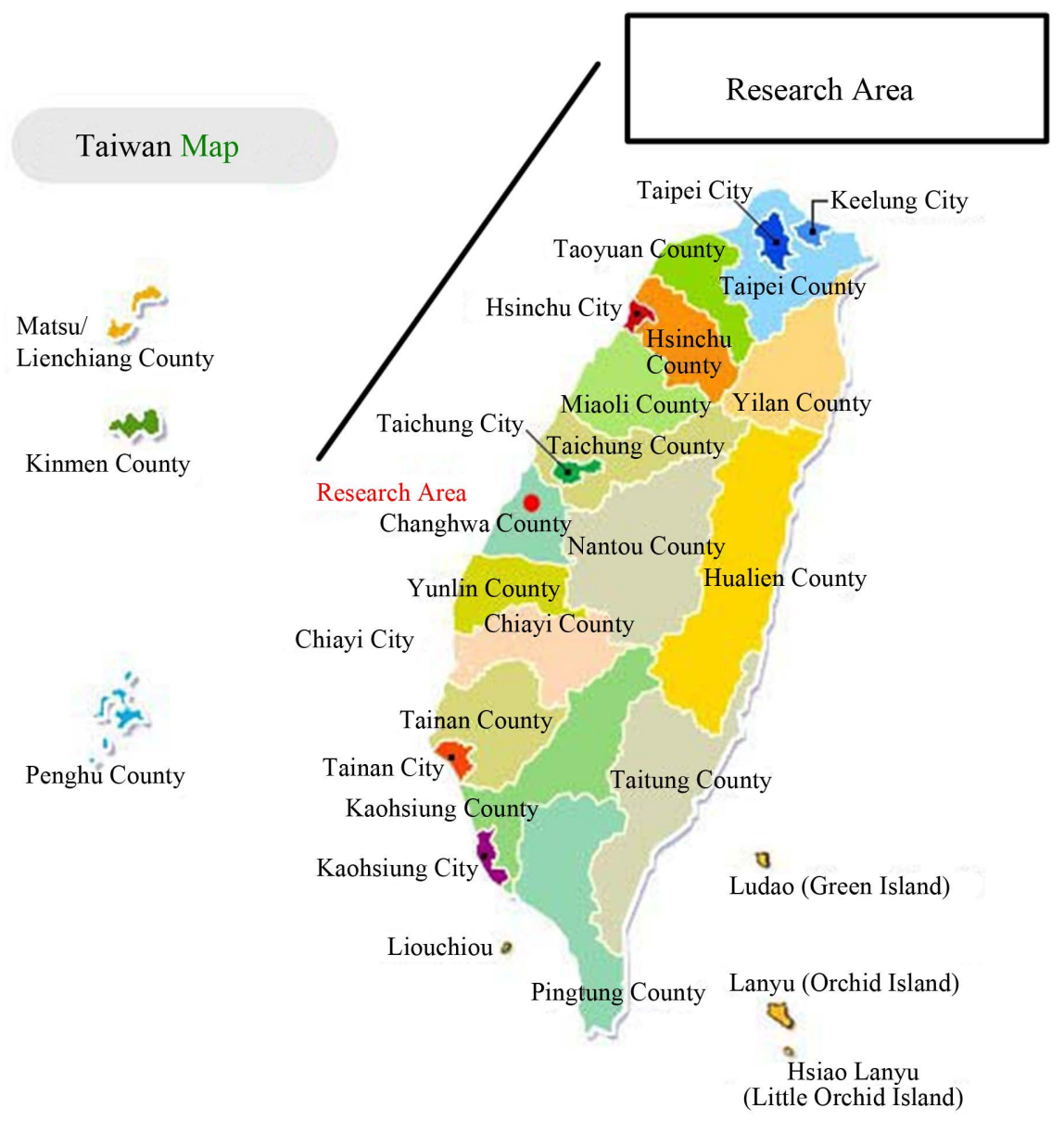

Figure 1. Location of research area, source: $\underline{\text { http://fangshiushiu.wordpress.com }}$

traction of factors and the rotation of the factors. Principal component analysis (PCA) and Varimax rotation available in SPSS was selected in this study. PCA is a widely used method for factor extraction. Factor weights are computed in order to extract the maximum possible variance, with successive factoring continuing until there is no further meaningful variance left. The factor model must then be rotated for analysis. The Cronbach's Alpha coefficients were 0.92 and 0.95 for the first part and second part of the questionnaire, and this implies a substantial degree of reliability.

Table 1 showed the results of the factor analysis for the purpose of validity test for the instrument of transformational leadership style. The results indicated that the questionnaire can explain $74.271 \%$ of the total variance for the data. Also, the eigenvalues of the 4 factors are also acceptable (should be higher than 1.00). To investigate whether the factor model is appropriate, KaiserMeyer-Olkin Measure and Barlett's Test of Sphericity available in SPSS is adopted in this study. The value of Kaiser-Meyer-Olkin Measure of Sampling Adequacy (KMO) is 0.89, and this value can be considered to be acceptable (should be 0.6 or above).
Table 2 showed the results of the factor analysis for the purpose of validity test for the instrument of transactional leadership style. The results indicated that the questionnaire can explain $80.56 \%$ of the total variance for the collected data. Also, the eigenvalues of the 3 factors are also acceptable (should be higher than 1.00). To investigate whether the factor model is appropriate, again, Kaiser-Meyer-Olkin Measure in SPSS is adopted in this study. The value of Kaiser-Meyer-Olkin Measure of Sampling Adequacy $(K M O)$ is 0.79 , and this value can be considered to be acceptable (should be 0.6 or above).

Table 3 showed the results of the factor analysis for the purpose of validity test for the instrument of students' learning motivation. The results indicated that the questionnaire can explain $54.01 \%$ of the total variance for the collected data. Also, the eigenvalues of the 3 factors are also acceptable (should be higher than 1.00). Again, to investigate whether the factor model is appropriate, again, Kaiser-Meyer-Olkin Measure available in SPSS is adopted in this study. The value of Kaiser-Meyer-Olkin Measure of Sampling Adequacy (KMO) is 0.78 , and this value can be considered to be acceptable (should be 0.6 or above). 
Table 1. Factor analysis of the instrument of transformational leadership style.

\begin{tabular}{|c|c|c|c|c|}
\hline No. of Items & Factor $1^{\mathrm{a}}$ & Factor $2^{\mathrm{b}}$ & Factor $3^{c}$ & Factor $4^{d}$ \\
\hline 10 & 0.795 & & & \\
\hline 12 & 0.754 & & & \\
\hline 11 & 0.752 & & & \\
\hline 7 & & 0.839 & & \\
\hline 9 & & 0.734 & & \\
\hline 8 & & 0.568 & & \\
\hline 2 & & & 0.788 & \\
\hline 1 & & & 0.756 & \\
\hline 3 & & & 0.598 & \\
\hline \multicolumn{5}{|l|}{5} \\
\hline \multicolumn{5}{|l|}{4} \\
\hline \multicolumn{5}{|l|}{6} \\
\hline Total eigenvalue & 2.534 & 2.391 & 2.174 & 1.813 \\
\hline$\%$ of variance & $21.118 \%$ & $19.922 \%$ & $18.120 \%$ & $15.111 \%$ \\
\hline $\begin{array}{l}\text { Cumulative \% } \\
\text { of variance }\end{array}$ & $21.118 \%$ & $41.041 \%$ & $59.160 \%$ & $74.271 \%$ \\
\hline$K M O=0.89$ & & & & \\
\hline
\end{tabular}

${ }^{\mathrm{a}}$ Factor 1: individualized consideration, ${ }^{\mathrm{b}}$ Factor 2: intellectual stimulation, ${ }^{c}$ Factor 3: charisma influences, ${ }^{\mathrm{d}}$ Factor 4: stimulating motivation.

Table 2. Factor analysis of the instrument of transactional leadership style.

\begin{tabular}{|c|c|c|c|}
\hline No. of Items & Factor $1^{\mathrm{a}}$ & Factor $2^{\mathrm{b}}$ & Factor $3^{c}$ \\
\hline 17 & 0.916 & & \\
\hline 16 & 0.884 & & \\
\hline 18 & 0.874 & & \\
\hline 13 & & 0.877 & \\
\hline 14 & & 0.856 & \\
\hline 15 & & 0.842 & \\
\hline 21 & & & 0.862 \\
\hline 19 & & & 0.837 \\
\hline 20 & & & 0.824 \\
\hline Total eigenvalue & 2.618 & 2.445 & 2.187 \\
\hline$\%$ of variance & $29.094 \%$ & $27.163 \%$ & $24.300 \%$ \\
\hline $\begin{array}{l}\text { Cumulative \% } \\
\text { of variance }\end{array}$ & $29.094 \%$ & $56.257 \%$ & $80.557 \%$ \\
\hline$K M O=0.79$ & & & \\
\hline
\end{tabular}

${ }^{\mathrm{a}}$ Factor 1: active management, ${ }^{\mathrm{b}}$ Factor 2: mutually beneficial award, ${ }^{\mathrm{c}}$ Factor 3: passive management.
Table 3. Factor analysis of the instrument of students' learning motivation.

\begin{tabular}{|c|c|c|c|}
\hline No. of Items & Factor $1^{\mathrm{a}}$ & Factor $2^{\mathrm{b}}$ & Factor $3^{c}$ \\
\hline 26 & 0.767 & & \\
\hline 24 & 0.748 & & \\
\hline 25 & 0.744 & & \\
\hline 22 & 0.715 & & \\
\hline 23 & 0.475 & & \\
\hline 31 & & 0.780 & \\
\hline 30 & & 0.677 & \\
\hline 32 & & 0.605 & \\
\hline 27 & & 0.580 & \\
\hline 28 & & 0.525 & \\
\hline 29 & & 0.524 & \\
\hline 34 & & & 0.816 \\
\hline 33 & & & 0.790 \\
\hline 35 & & & 0.714 \\
\hline Total eigenvalue & 2.790 & 2.500 & 2.272 \\
\hline$\%$ of variance & $19.929 \%$ & $17.857 \%$ & $16.225 \%$ \\
\hline $\begin{array}{l}\text { Cumulative \% } \\
\text { of variance }\end{array}$ & $19.929 \%$ & $37.786 \%$ & $54.011 \%$ \\
\hline$K M O=0.78$ & & & \\
\hline
\end{tabular}

${ }^{\mathrm{a}}$ Factor 1: Value, ${ }^{\mathrm{b}}$ Factor 2: Expectation, ${ }^{\mathrm{c}}$ Factor 3: Emotion.

\subsection{Data Analyses}

The descriptive statistics, Pearson product-moment correlation analysis and stepwise multiple regression analysis available in SPSS Statistical Package were selected in this study. The descriptive statistics is used to provide a general understanding of the collected data. Pearson product-moment correlation analysis and multiple regression analysis are adopted to investigate the correlation and causal relationship between leadership styles of teachers and learning motivation of students.

\section{Results and Discussions}

\subsection{General Information}

The results for the descriptive statistical analysis on the seven factors of the two leadership styles were shown in Table 4. The mean score, standard deviation (SD) and ranking of the two leadership styles were calculated.

For the transformation leadership style (see Table 4), it can be seen that the charisma influences factor performed the maximum average score $(\mathrm{M}=4.44$; ranking = 1), while the stimulating motivation factor exhibited the 
Table 4. Descriptive statistics results of two leadership styles $(N=\mathbf{2 8 0 0})$.

\begin{tabular}{|c|c|c|c|c|}
\hline Leadership styles & factor & mean score & SD. & ranking \\
\hline \multirow[t]{4}{*}{$\begin{array}{c}\text { Transformation } \\
\text { leadership }\end{array}$} & $\begin{array}{l}\text { 1. charisma } \\
\text { influences }\end{array}$ & 4.4410 & 0.74288 & 1 \\
\hline & $\begin{array}{l}\text { 2. stimulating } \\
\text { motivation }\end{array}$ & 3.4683 & 1.13624 & 4 \\
\hline & $\begin{array}{l}\text { 3. intellectual } \\
\text { stimulation }\end{array}$ & 3.8339 & 1.05950 & 2 \\
\hline & $\begin{array}{l}\text { 4. individualized } \\
\text { consideration }\end{array}$ & 3.7756 & 1.00868 & 3 \\
\hline Average score & & 3.7759 & 0.85776 & \\
\hline \multirow[t]{3}{*}{$\begin{array}{c}\text { Transactional } \\
\text { leadership }\end{array}$} & $\begin{array}{l}\text { 1. mutually } \\
\text { beneficial award }\end{array}$ & 3.1767 & 1.33541 & 3 \\
\hline & $\begin{array}{c}\text { 2. active } \\
\text { management }\end{array}$ & 4.4048 & 0.80503 & 1 \\
\hline & $\begin{array}{l}\text { 3. passive } \\
\text { management }\end{array}$ & 3.2499 & 1.14904 & 2 \\
\hline $\begin{array}{c}\text { Aggregate } \\
\text { average score }\end{array}$ & & 3.6104 & 0.86962 & \\
\hline
\end{tabular}

minimum average score $(\mathrm{M}=3.47$; ranking = 4). For the transactional leadership style, the active management factor performed the maximum average score $(\mathrm{M}=4.41$; ranking $=1$ ), while the mutually beneficial award factor exhibited the minimum average score $(\mathrm{M}=3.18$; ranking = 3).

Moreover, it can be seen that the average scores for the above two leadership style are 3.78 and 3.61 (see Table 4), respectively. As mentioned before, five-point rating scale of Likert Type was adopted in this study. The above results imply that the most frequently ratings filled in by students are 3 and 4 . That is to say, "agree" and "partially agree” are most frequently selected by students. In other words, most students in the research area thought that their teachers have adopted both the above two leadership styles.

The results for the descriptive statistical analysis on the three factors of the learning motivation of students were shown in Table 5. The mean score, standard deviation (SD) and ranking were calculated. It can be seen that the value factor performed the maximum average score $(\mathrm{M}=4.17$; ranking $=1)$, while the emotion factor exhibited the minimum average score $(\mathrm{M}=3.11$; ranking $=3)$. Moreover, it can be seen that the average score for the learning motivation of students is 3.87 (see Table 5). Again, the above results imply that the most frequently ratings filled in by students are 3 and 4 . That is to say, "agree" and "partially agree" are most frequently selected by students.

\subsection{The Correlation between Leadership Styles and Learning Motivation}

\subsubsection{Transformational Leadership Style and Learning Motivation}

The correlation coefficients $(r)$ between dependent varia-
Table 5. Descriptive statistics results for learning motivation of students $(N=\mathbf{2 8 0 0})$.

\begin{tabular}{ccccc}
\hline $\begin{array}{c}\text { Learning } \\
\text { motivation }\end{array}$ & factor & $\begin{array}{c}\text { Mean } \\
\text { Score }\end{array}$ & SD & ranking \\
\hline $\begin{array}{c}\text { Learning motivation } \\
\text { of students }\end{array}$ & 1. Value & 4.1664 & 0.85088 & 1 \\
& 2. Expectancy & 4.0109 & 0.77048 & 2 \\
& 3. Affective & 3.1114 & 1.36887 & 3 \\
$\begin{array}{c}\text { Aggregate } \\
\text { average score }\end{array}$ & & 3.8737 & 0.72463 & \\
\hline
\end{tabular}

ble (learning motivation of students) and independent variable (transformational leadership style) were showed in Table 6. Table 6 showed that learning motivation of students and transformational leadership style are all positive correlation. Moreover, Except the correlation between emotion factor and transformational leadership style is low correlated ( $r=0.18, r=0.24, r=0.25, r=$ $0.28, r=0.31)$. Other correlations are considered to be moderately correlated.

\subsubsection{Transactional Leadership Style and Learning Motivation}

The correlation coefficients $(r)$ between dependent variable (learning motivation of students) and independent variable (transactional leadership style) were showed in Table 7. Table 7 showed that learning motivation of students and transactional leadership style are all positive correlation. Only two correlation coefficients $(r)$ are low correlated ( $r=0.15$ and $r=0.34$ ). Other correlations are considered to be moderately correlated.

\subsection{The Causal Relationship between the Leadership Styles of Teachers and Learning Motivation of Students}

The results of the multiple regression analysis were shown in this section. Seven independent variables (charisma influences, stimulating motivation, intellectual stimulation, individualized consideration, mutually beneficial award, active management and passive management) have been selected into the regression equation. Table 8 showed the coefficient of determination (denoted $R^{2}$ ) obtained from the regression analysis using SPSS statistics software, indicated how well data points fit a line or curve. The results showed that the value of adjust $R$ Squared is 0.53 for all the seven independent variables (Table 8) which implies that the mutiple regression equation can explain $52.60 \%$ of variance for the learning motivation of students.

Based on the aforementioned regression analysis, the following model can be postulated as a prediction tool.

$\mathrm{Y}$ (learning motivation) $=0.195 \times \mathrm{X}_{1}$ (individualized consideration) $+0.279 \times \mathrm{X}_{2}$ (passive management) + 
Table 6. Correlations between transformational leadership style and learning motivation $(N=2800)$.

\begin{tabular}{|c|c|c|c|c|c|}
\hline \multirow{2}{*}{$\begin{array}{c}\text { Correlation }(r) \\
\text { Learning } \\
\text { motivation factor }\end{array}$} & \multicolumn{5}{|c|}{$\underline{\text { Transformational leadership factor }}$} \\
\hline & $\begin{array}{l}\text { charisma } \\
\text { influences }\end{array}$ & $\begin{array}{l}\text { stimulating } \\
\text { motivation }\end{array}$ & $\begin{array}{l}\text { intellectual } \\
\text { stimulation }\end{array}$ & $\begin{array}{c}\text { individualized } \\
\text { consideration }\end{array}$ & $\begin{array}{c}\text { aggregate } \\
\text { transformational leadership }\end{array}$ \\
\hline \multicolumn{6}{|l|}{ Learning motivation factor } \\
\hline Value & $0.567^{* *}$ & $0.487^{* *}$ & $0.534^{* *}$ & $0.558^{* *}$ & $0.608^{* *}$ \\
\hline Expectancy & $0.510^{* *}$ & $0.497^{* *}$ & $0.558^{* *}$ & $0.569^{* *}$ & $0.621^{* *}$ \\
\hline Affective & $0.177^{* *}$ & $0.242^{* *}$ & $0.245^{* *}$ & $0.281^{* *}$ & $0.306^{* *}$ \\
\hline Aggregate learning motivation & $0.542^{* *}$ & $0.528^{* *}$ & $0.578^{* *}$ & $0.607^{* *}$ & $0.661^{* *}$ \\
\hline
\end{tabular}

${ }^{* *} p<0.01,{ }^{* *}$ Correlation is significant at the 0.01 level (2-tailed).

Table 7. Correlations between transactional leadership style and learning motivation $(N=\mathbf{2 8 0 0})$.

\begin{tabular}{|c|c|c|c|c|}
\hline Correlation $(r)$ & \multicolumn{4}{|c|}{$\underline{\text { Transformational leadership factor }}$} \\
\hline Learning motivation factor & $\begin{array}{c}\text { Contingent reward } \\
\text { (mutually beneficial award) }\end{array}$ & $\begin{array}{c}\text { Active } \\
\text { management }\end{array}$ & $\begin{array}{c}\text { Passive } \\
\text { management }\end{array}$ & $\begin{array}{c}\text { Aggregate } \\
\text { transactional leadership }\end{array}$ \\
\hline \multicolumn{5}{|l|}{ Learning motivation factor } \\
\hline Value & $0.412^{* *}$ & $0.548^{* *}$ & $0.344^{* *}$ & $0.531^{* *}$ \\
\hline Expectancy & $0.453^{* *}$ & $0.525^{* *}$ & $0.443^{* *}$ & $0.589^{* *}$ \\
\hline Affective & $0.345^{* *}$ & $0.154^{* *}$ & $0.439^{* *}$ & $0.418^{* *}$ \\
\hline Aggregate learning motivation & $0.519^{* *}$ & $0.531^{* *}$ & $0.523^{* *}$ & $0.660^{* *}$ \\
\hline
\end{tabular}

${ }^{* *} p<0.01,{ }^{* *}$ Correlation is significant at the 0.01 level (2-tailed).

Table 8. Coefficient of determination $\left(R^{2}\right)$ obtained from the regression analysis $(N=2800)$.

\begin{tabular}{ccccc}
\hline Independent variables & $R$ & Adjust $R$-squared & $R$-squared change & $F$ value \\
\hline Individualized consideration & 0.607 & 0.368 & 0.368 & $1,630.089^{* * *}$ \\
individualized consideration & 0.685 & 0.469 & 0.101 & $535.178^{* * *}$ \\
passive management & 0.712 & 0.506 & 0.037 & $211.130^{* * *}$ \\
Intellectual stimulation & 0.721 & 0.520 & 0.013 & $78.105^{* * *}$ \\
Active management & 0.724 & 0.524 & 0.004 & $25.772^{* * *}$ \\
Stimulating motivation & 0.726 & 0.525 & 0.002 & $11.037^{* * *}$ \\
Award mutually beneficially & 0.726 & 0.526 & 0.001 & $4.569^{* * *}$
\end{tabular}

$P=0.000,{ }^{* * *} p<0.001$, Correlation is significant at the 0.01 level (2-tailed).

$0.178 \times \mathrm{X}_{3}$ (charisma influences) $+0.119 \times \mathrm{X}_{4}$ (intellectual stimulation $)+0.096 \times \mathrm{X}_{5}$ (active management) + $0.049 \times \mathrm{X}_{6}$ (stimulating motivation $)+0.042 \times \mathrm{X}_{7}$ (award mutually beneficially)

\section{Conclusions and Recommendations}

\subsection{Conclusions}

According to the above-mentioned analysis results, the following conclusions were drawn:

1) From the above study results, it can be found that both the transformational and transactional leadership styles have been employed by elementary school teachers in Changhua County of Taiwan.

2) The correlations between the above two leadership styles and the learning motivation of students are both "moderate to good relationship".

3) The transformational and the transactional leadership styles can explain $52.60 \%$ of variance for the learning motivation of students

4) Multiple regression analysis can be used to infer causal relationships between the leadership styles of 
teachers and the learning motivation of students.

\subsection{Recommendations}

The author proposes the following recommendations for schools and teachers who would like to engage in instructional innovation.

1) According to the study results, the coefficient of determination $\left(R^{2}\right)$ for the individual consideration factor of the transformational leadership style is 0.37 , which implies that the individual consideration factor can explain $36.80 \%$ of the learning motivation of students. Therefore, it is suggested that teachers can employ the individual consideration in the leadership style to support various individual consideration according to different student types.

2) According to the study results, the sum of the coefficient of determination $\left(R^{2}\right)$ for the seven factors of the transformational leadership and transactional leadership styles is 0.526 . This implies that the above two leadership styles can explain $52.6 \%$ of the learning motivation of students. Therefore, if a teacher can employ both the above leadership styles, the learning motivation of students can be well stimulated.

3) Students' learning motivation could be affected by several factors, for example: social factor, family factor, school environmental factor, teacher's factor, student's personal factor, etc. This study focused on the relationship between teachers' leadership styles and students' learning motivation. Other factors could be further investigated in future work.

4) Only quantitative analysis has been adopted in this study. It is suggested that qualitative research method could be employed in future work to provide more useful information for students' learning motivation.

\section{REFERENCES}

[1] M. R. Awan and K. Mahmood. "Relationship among Leadership Style, Organizational Culture and Employee Commitment in University Libraries,” Library Management, Vol. 31, No. 4-5, 2010, pp. 253-266. http://dx.doi.org/10.1108/01435121011046326

[2] S. P. Robbins and M. Coultar, "Management," 8th Edition, Pearson Education, Inc., Delhi, 2005.

[3] P. F. Drucker, "The Executive in Action: Managing for Results Innovation and Entrepreneurship,” Harper Collins, New York, 1996.

[4] B. M. Bass, "From Transactional to Transformational Leadership: Learning to Share the Vision," Organizational Dynamics, Vol. 18, No. 3, 1990, pp. 19-31. http://dx.doi.org/10.1016/0090-2616(90)90061-S

[5] B. M. Bass, "Handbook of Leadership,” Free Press, New York, 1990.

[6] S. Kassin, "Psychology,” Prentice-Hall, Inc., Upper Saddle River, 2003.
[7] J. Adair, “The Skills of Leadership,” Aldershot, Gower, 1984.

[8] J. B. Miner, “Organizational Behavior 1: Essential Theories of Motivation and Leadership,” M.E. Sharpe, Inc., New York, 2006.

[9] D. M. Kagan, "Implications of Research on Teacher Belief,” Educational Psychologist, Vol. 27, No. 1, 1992, pp. 65-90. http://dx.doi.org/10.1207/s15326985ep2701 6

[10] R. Kane, S. Sandretto and C. Heath, "Telling Half the Story: A Critical Review of Research on the Teaching Beliefs and Practices of University Academics," Review of Educational Research, Vol. 72, No. 2, 2002, pp. 177228. http://dx.doi.org/10.3102/00346543072002177

[11] M. F. Pajares, “Teachers' Beliefs and Educational Research: Cleaning up a Messy Construct," Review of Educational Research, Vol. 62, No. 3, 1992, pp. 307-332. http://dx.doi.org/10.3102/00346543062003307

[12] F. Marieke, K. M. Stokking and N. Verloop, "Teacher Beliefs and Teacher Behaviour in Portfolio Assessment," Teaching and Teacher Education, Vol. 24, No. 7, 2008, pp. 1691-1704.

http://dx.doi.org/10.1016/j.tate.2008.02.021

[13] Wikipedia, “Transforming Leadership,” 2014. http://en.wikipedia.org/wiki/Transformational leadership

[14] J. Rhodes, P. Walsh and P. Lok, "Convergence and Divergence Issues in Strategic Management-Indonesia's Experience with the Balanced Scorecard in HR Management," The International Journal of Human Resources Management, Vol. 19, No. 6, 2008, pp. 1170-1185. http://dx.doi.org/10.1080/09585190802051477

[15] B. A. Kaifi and B. G. Mujtaba, "Transformational Leadership of Afghans and Americans: A Study of Culture, Age and Gender," Journal of Service Science and Management, Vol. 3, No. 1, 2010, pp. 150-158.

[16] J. M. Burns, "Leadership,” Harper \& Row, New York, 1978.

[17] B. M. Bass and R. E. Riggio, "Transformational Leadership,” 2nd Edition, Lawrence Erlbaum Associates, Mahwah, 2006.

[18] B. M. Bass, "Leadership and Performance beyond Expectations,” Free Press, New York, 1985.

[19] B. M. Bass, "The Future of Leadership in Learning Organizations," Journal of Leadership \& Organizational Studies, Vol. 7, No. 3, 2000, pp. 18-40. http://dx.doi.org/10.1177/107179190000700302

[20] D. Tengilimoğlu, “A Field Study for Detecting the Leadership Behavior Features in Public and Private Sector Organizations,” Electronic Social Sciences Journal, Vol. 4, 2005, pp. 1-16.

[21] E. Karip, “Transformational Leadership,” Educational Administration in Theory and Practice, Vol. 4, No. 16, 1998, pp. 443-465.

[22] B. M. Bass and P. Steidlmeier, "Ethics, Character, and Authentic Transformational Leadership Behavior,” Leadership Quarterly, Vol. 10, 1999, pp. 181-217. http://dx.doi.org/10.1177/107179190000700302

[23] D. Schater, "Psychology," Catherine Woods, New York 
City, 2011, p. 325.

[24] J. A. Fredricks, P. C. Blumenfeld, and A. H. Paris, "School Engagement: Potential of the Concept, State of Evidence," Review of Educational Research, Vol. 74, No. 1, 2004, pp. 59-109. http://dx.doi.org/10.3102/00346543074001059

[25] J. E. Ormrod, "How Motivation Affects Learning and Behavior,” Pearson Allyn Bacon Prentice Hall, Boston, 2010.

[26] S. G. Paris and J. C. Turner, "Situated Motivation,” In: P. Pintrich, D. Brown and C. E. Weinstein, Eds., Student Notivation, Cognition, and Learning: Essays in Honor of Wilbert J. McKeachie, Lawrence Erlbaum, Hillsdale, 1994, pp. 213-237.

[27] R. Rueda and L. C. Moll, "A Sociocultural Approach to Motivation,” In: H. F. O’Neill and M. Drillings, Eds., Motivation: Theory and Research, Lawrence Erlbaum Associates, Hillsdale, 1994, pp. 117-136.

[28] H. H. Huang, "A Study of the Relationship between the Leadership Styles of Teachers and the Achievement Motivation of Students in Elementary Schools,” Master the- sis of Graduate Institute of Educational Administration. National Pingtung University of Science and Technology, Pingtung, 1999.

[29] J. J. Wu and B. L. Cherng, "Revised Form for Learning Strategies,” Psychological Testing, Vol. 39, 2003, pp. 5978.

[30] P. R. Pintrich, D. A. F. Smith, T. Garcia and W. J. McKeachie, "A Manual for the Use of the Motivated Strategies for Learning Questionnaire (MSLQ). Mich: National Center for Research to Improve Postsecondary Teaching and Learning (NCRIPTAL)," School of Education, The University Michigan, Ann Arbor, 1989.

[31] S. C. Huang, "The Relationships among Learning Motivation, Learning Strategies and Academic Achievement of Aboriginal Junior High School Students,” Master thesis in Education Institution, National Changhua University of Education, Changhua City, 2003.

[32] J. C. Nunnally, "Psychometric Theory," 2nd Edition, McGraw-Hill, New York, 1978. 